\title{
Risk Prevention of the Rural Idle Homesteads Transfer in Nanhai District of Foshan City based on the System for Separating Rural Land Ownership Rights
}

\author{
Jinwei Huang a, Haoyi Chen \\ School of Management, Guangdong University of Technology, Guangzhou, Guangdong, 510520, \\ China \\ a1357827936@qq.com
}

\begin{abstract}
With the comprehensive deepening of the new round of rural land reform and the acceleration of urbanization, we urgently need to pre-judge and protect the risks in the process of homestead transfer, to clarify, correct and summarize the deficiencies of the transfer system, and to develop, perfect and innovate in practice, so as to reduce the risks encountered by farmers in the process of transferring Homestead, and strengthen farmers' willingness to transfer. Taking Nanhai District of Foshan City, one of the 33 pilot projects of the System for Separating the Ownership rights as an example, this paper analyzes and summarizes the risk factors in the process of rural idle homestead transfer from the perspective of farmers by using the method of questionnaire survey and binary logistic regression analysis model. Through logistic regression analysis, it is found that farmers' willingness to transfer homestead in Nanhai District are significantly connected with six variables including farmer's occupation and number of homestead. Based on the regression results, this paper will put forward countermeasures to local government to avoid the risk of homestead transfer for the sake of better homestead circulation.
\end{abstract}

Keywords: System for Separating Rural Land Ownership Rights; Rural Homestead Land Use-right; Risk Prevention.

\section{Background of the Proposal of System for Separating Rural Land Ownership Rights}

Rural homestead is a welfare policy issued by the government in order to narrow the gap between urban and rural economic development. In order to ensure the preferential nature of homestead for farmers, the government severely restricted the transfer scope of homestead within the villages' collective economic organizations, but the urban land system has no such serious restrictions. On the contrary, the difference between the two land systems has aggravated the economic gap between urban and rural areas in China[1]. It is also the awareness of this phenomenon that made our country begin to explore the transfer policy of homestead gradually. Before the system for separating rural land ownership rights was issued, there is no strict rules and regulations to prohibit the transfer of the right to use homestead in the law. However, the law related to the transfer is imcomplete and the operation procedures are complicated, which arouses many process problems. Secondly, the development of the land market mechanism in our country is not perfect, which exerts great monopoly and inequality, and the transfer of homestead lacks effective guidance. Based on the above reasons, the transfer of rural homestead in our country has great risks, and the transfer willingness of rural homestead is not widely high.

In the early stage of China's urbanization, the problem of the rural homestead transfer is not much of a problem, because at this time, farmers have not entered the city in large quantities to work, although the transfer of residential land is difficult, but the existing population in the countryside is large, the phenomenon that rural homestead being idled is not obvious. However, after entering the 21 st century, China's urbanization process is accelerating continuously, with the urbanization rate maintaining an annual growth rate of about $1.01 \%$. At the end of 2018, China's urbanization rate reached $59.58 \%$, which indicates that China's urbanization has entered a high-speed development stage[2]. At the same time, various contradictions in agricultural development began to emerge 
gradually. Farmers living in the countryside themselves are more eager for the prosperity of the city. Meanwhile, with the improvement of agricultural production technology, most of the liberated labor force will choose to work in the city, causing a large number of rural people to flow out[3]. Many of these people have applied for homestead, and farmers have two methods to dispose their homesteads after entering the city in the premise of retaining their homesteads. One is circulation, the other to idle them. In the process of circulation, farmers' risk awareness determines their willingness to transfer. If the risk of homestead transfer is relatively high, then farmers' willingness to circulate is not strong. In order to avoid the risk of transfer, they would rather make it idle and not carry out the transfer, thus wasting land resources[4]. According to official data, at this stage, rural residential land covers an area of more than 200 million $m u$ ( $=0.0667$ hectares) in the country, among which 10\%$15 \%$ of residential land has been idle for a long time--five years[5]. At the same time, with the acceleration of urbanization, the number of homesteads being idled and the coverage of them decrease, and the system for separating rural land ownership rights can ensure that farmers do not need to withdraw from their homesteads if they retain their ownerships, and the transfer of management rights can guarantee the property income.

At present, after the trial implementation of the system of system for separating rural land ownership rights in the national pilot areas, it has been found that there are problems in the circulation of homestead, such as unclear ownership, small circulation scope, and imperfect construction of relevant policy system[6]. The incomplete system for separating rural land ownership rights makes farmers face high risks when transferring their own homestead. They are afraid that they will lose their own homesteads after transferring them, which means that they may lose their final security, so they give up the transfer of homestead. It is precisely because of the high risk of the homestead transfer that the farmers are not willing to do that, and it is difficult to promote the reform process of homestead. For this reason, from the perspective of farmers, this paper analyzes the risk factors of farmers' concern by issuing questionnaires to farmers in Nanhai District of Foshan City, and constructs a logistic model to establish a complete risk prevention mechanism in view of the current situation of homestead in Nanhai District of Foshan City, so as to reduce the risk of homestead transfer, strengthen the will of transfer, activate the idle homestead to a large extend, and alleviate the pressure of land resources shortage.

\section{Source of Data, Variable Selection and Method}

\subsection{Source of Data}

The data used in this study are from the survey of households' willingness to transfer rural homestead in Nanhai District, Foshan City in July 2019. The survey adopts a random sampling method, and selects five villages (Neigangdong village, Dalibiao village, Longwan village, Huanghe village and Fengxi village) in Nanhai District to conduct questionnaire survey and field investigation. The content of the questionnaire was designed according to 14 independent variables and 1 dependent variable. A total of 126 questionnaires were distributed and retrieved during the investigation process, of which 110 were valid, accounting for $87.30 \%$ of the total number of questionnaires, and 16 were invalid, representing $12.70 \%$. The core question is set as "whether to be willing to transfer homestead,"and the answer is set as "willing" and "unwilling". The choice of willing conditions is defined as $\mathrm{P}=1$, and unwilling is defined as $\mathrm{P}=0$. Of the 110 valid survey objects interviewed, only 29 were willing to transfer, while 81 were unwilling, and the farmers' willingness to transfer was relatively low.

\subsection{Variable Selection and Assignment}

Determination of the independent variable. After learning from the research results of Cui\&Fang and other scholars on farmers' willingness to transfer homestead, the independent variables in this paper are mainly selected from the three dimensions of individual characteristics, basic conditions of family and homestead information. Variables that reflect individual characteristics of farmers. It 
mainly includes the farmer's gender, age, education level and occupation type; the variables of the basic condition of the farmer's family mainly include the total family population, the number of labor force, the number of migrant workers(out), the main source of income and the family's annual income; the variables of homestead information mainly include the number of the homestead, the coverage of the homestead, the distance from the government, the utilization status and the housing age. See Table 1 for details of variables.

Table 1. Explanation and Description of Variables

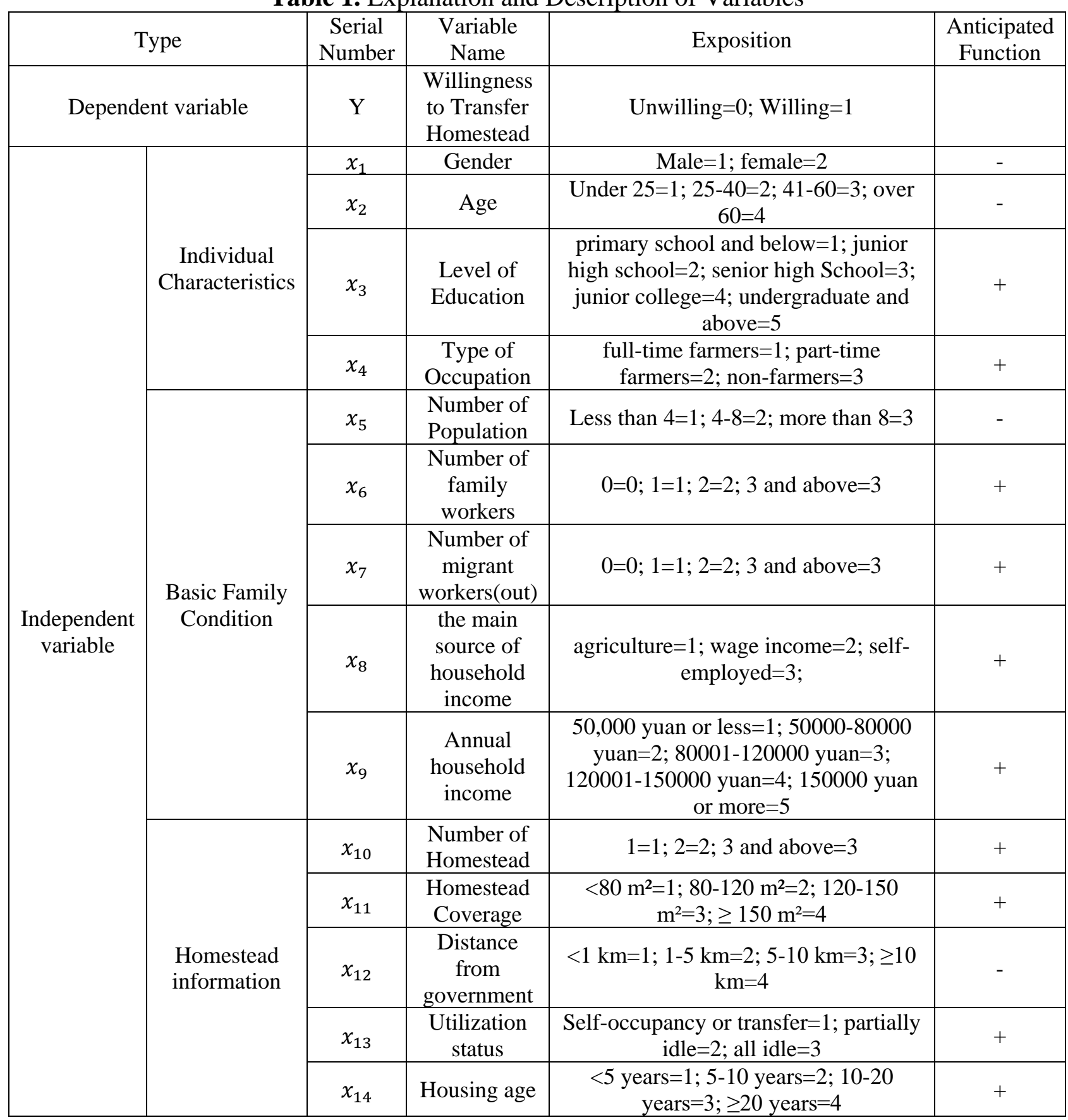

The dependent variables in this study are binary variables, so the data in this study are mainly discrete data. Therefore, a binary logistic regression model was chosen to test the correlation between two dependent variables and several independent variables. The specific form of the logistic regression analysis model is as follows: 
Volume 13 (2021)

$$
\begin{gathered}
\mathrm{Y}=\ln \left[\frac{\mathrm{p}}{1-\mathrm{p}}\right]=\mathrm{f}(\mathrm{x})=\alpha+\beta_{1} \mathrm{x}_{1}+\beta_{2} \mathrm{x}_{2}+\cdots \cdots+\beta_{14} \mathrm{x}_{14}+\varepsilon \\
\mathrm{p}=\frac{\mathrm{e}^{\mathrm{f}(\mathrm{x})}}{1+\mathrm{e}^{\mathrm{f}(\mathrm{x})}} \\
1-\mathrm{p}=\frac{1}{1+\mathrm{e}^{\mathrm{f}(\mathrm{x})}}
\end{gathered}
$$

In the formula, $\mathrm{Y}$ is the willingness of the peasants to transfer the homestead, i.e., whether they are willing to transfer; $\mathrm{P}$ is the probability of the peasants willing to transfer the homestead; $1-\mathrm{p}$ is the probability of the peasants unwilling to transfer the homestead; is the I-th independent variable that affects the peasants' willingness to transfer; is the influence coefficient of the I-th explanatory variable; $\alpha$ is a constant term; and $\varepsilon$ is the error. ( $\mathrm{i}=1,2,3, \ldots, 14)$.

\section{Result Analysis}

\subsection{Model Fitting Test}

This paper uses SPSS 25.0 statistical analysis software to analyze the influencing factors of farmer's willingness of transferring rural homestead in Nanhai District. In order to test whether the established model can be used to analyze the problems, the significance and fitness of the overall model coefficients of the established model were tested before running. In the model test, the P-value operation result is 0.029 , which is less than 0.05 significant level, and the model is established. According Hosmer-Lemeshow test, the significance is 0.403 , which is far more than 0.05; for the whole model, the logarithmic likelihood value of -2 is 101.289 , and the values of Cox\&Snell's ${ }^{2}$ and Nagelkerke's ${ }^{2}$ are 0.208 and 0.303 respectively. In conclusion, the model has good fitting degree, and the prediction result of the model can better reflect the influence degree of each variable on the farmers' residence land transfer intention.

\subsection{Model Results and Analysis}

SPSS 25.0 software was used to carry out logistic regression analysis on the questionnaire data, and "input" was selected as the regression method. The processing results are shown in Table 2.

According to the significance value in Table 2, the independent variables which have obvious influence on farmers' willingness to transfer homestead are as follows: the occupation type of farmers (0.135), the number of homestead (0.143), the coverage of Homestead (0.039), the distance from government (0.095), the utilization status $(0.067)$ and the housing age (0.051). The influence coefficients from large to small are: housing age (1.154), residential land area (0.885), utilization status (0.742), number of residential land (0.632), distance from government (-0.509), and occupation type (0.459). The specific analysis is as follows:

(1) The occupation types of farmers: In the occupation of farmers, the less the proportion of agriculture-related occupation is, the less farmers need to live in the countryside. At the same time, their occupation often needs to live in cities and towns for better work, and the housing land for this kind of family's living role is relatively limited, so their willingness to transfer homestead will be greater. Therefore, farmers engaged in Non-agricultural occupation type of work has a strengthening effect on the transfer will.

(2) Number of homesteads.

Due to the concept of large families in the countryside, families with multiple homesteads basically gather in one of them, and the others may be to stand idle. In the case of meeting their own family's housing needs, if they can get additional income through the transfer of idle homestead, farmers' willingness of transfer will be greater. Therefore, the number of homesteads also has a strengthened effect on the intention of transfer. 
Table 2. Processing returns based on sample model

\begin{tabular}{|c|c|c|c|c|c|c|c|c|}
\hline \multirow{2}{*}{$\begin{array}{l}\text { Serial } \\
\text { Number }\end{array}$} & \multirow{2}{*}{$\begin{array}{l}\text { Variable } \\
\text { Name }\end{array}$} & \multirow{2}{*}{$\begin{array}{l}\text { Regression } \\
\text { coefficient }\end{array}$} & \multirow{2}{*}{$\begin{array}{l}\text { Standard } \\
\text { deviation }\end{array}$} & \multirow{2}{*}{ Wals } & \multirow{2}{*}{ Significance } & \multirow{2}{*}{$\operatorname{Exp}(B)$} & \multicolumn{2}{|c|}{$\begin{array}{l}\text { 95\% Confidence } \\
\text { Interval }\end{array}$} \\
\hline & & & & & & & $\begin{array}{l}\text { Minimum } \\
\text { value }\end{array}$ & $\begin{array}{l}\text { Maximum } \\
\text { value }\end{array}$ \\
\hline$x_{1}$ & Gender & -0.426 & 0.574 & 0.549 & 0.459 & 0.653 & 0.212 & 2.014 \\
\hline$x_{2}$ & Age & -0.075 & 0.357 & 0.044 & 0.834 & 0.928 & 0.461 & 1.868 \\
\hline$x_{3}$ & $\begin{array}{l}\text { Level of } \\
\text { Education }\end{array}$ & 0.147 & 0.234 & 0.391 & 0.532 & 1.158 & 0.732 & 1.833 \\
\hline$x_{4}$ & $\begin{array}{c}\text { Type of } \\
\text { Occupation }\end{array}$ & $0.459^{*}$ & 0.307 & 2.234 & 0.135 & 1.582 & 0.867 & 2.887 \\
\hline$x_{5}$ & $\begin{array}{l}\text { Number of } \\
\text { Population }\end{array}$ & -0.650 & 0.582 & 1.249 & 0.264 & 0.522 & 0.167 & 1.633 \\
\hline$x_{6}$ & $\begin{array}{l}\text { Number of } \\
\text { family } \\
\text { workers }\end{array}$ & 0.165 & 0.541 & 0.093 & 0.761 & 1.179 & 0.408 & 3.405 \\
\hline$x_{7}$ & $\begin{array}{c}\text { Number of } \\
\text { migrant } \\
\text { workers(out) }\end{array}$ & 0.280 & 0.246 & 1.302 & 0.254 & 1.324 & 0.818 & 2.142 \\
\hline$x_{8}$ & $\begin{array}{l}\text { the main } \\
\text { source of } \\
\text { household } \\
\text { income }\end{array}$ & 0.004 & 0.395 & 0.000 & 0.993 & 1.004 & 0.462 & 2.178 \\
\hline$x_{9}$ & $\begin{array}{c}\text { Annual } \\
\text { household } \\
\text { income }\end{array}$ & 0.110 & 0.247 & 0.199 & 0.656 & 1.117 & 0.688 & 1.813 \\
\hline$x_{10}$ & $\begin{array}{l}\text { Number of } \\
\text { Homestead }\end{array}$ & $0.632^{*}$ & 0.431 & 2.149 & 0.143 & 1.881 & 0.808 & 4.378 \\
\hline$x_{11}$ & $\begin{array}{l}\text { Homestead } \\
\text { Coverage }\end{array}$ & $0.885^{* * *}$ & 0.428 & 4.279 & 0.039 & 2.422 & 1.048 & 5.602 \\
\hline$x_{12}$ & $\begin{array}{l}\text { Distance } \\
\text { from } \\
\text { government }\end{array}$ & $-0.509^{*}$ & 0.305 & 2.788 & 0.095 & 0.601 & 0.331 & 1.092 \\
\hline$x_{13}$ & $\begin{array}{l}\text { Utilization } \\
\text { status }\end{array}$ & $0.742^{* *}$ & 0.406 & 3.345 & 0.067 & 2.101 & 0.948 & 4.655 \\
\hline$x_{14}$ & Housing age & $1.154^{* *}$ & 0.592 & 3.796 & 0.051 & 3.171 & 0.993 & 10.126 \\
\hline
\end{tabular}

Note:"*", "**" and "***" indicate significant correlation at 15\%, 10\%, and 5\% levels, respectively.

(3) Relative area of homestead.

The area of homestead that every farmer can use is certain. The larger the relative area of the homestead, the more likely the rested part of homestead is not used. Meanwhile, a family with a large area of homestead means that the family may be better off financially and can also live smoothly in the city after transferring the homestead. The security function of homestead for these family is not strong, and the risk of their transfer is relatively small. Therefore, the relative area of the homestead is also a driving force for homestead transfer.

(4) Location

Farther away from the city center means bad location conditions, so the value of the homestead circulation is lower, and it is difficult to meet the market demand. In addition, living in remote areas may have a lower standard of living, so they will be very dependent on homestead, and consequently they are unwilling to give it up. Therefore, the farther the distance to the central areas, the lower the homestead transfer willingness will be.

(5) Utilization status.

If idle homesteads are more commonly-seen, homestead will play a smaller role for farmers, and farmers will be more inclined to transfer these idle homestead resources to obtain additional income 
under the protection of the system. Therefore, the idle situation has an enhanced effect on the homestead transfer intention.

(6) Housing age: Long housing age of the homestead denotes that many living facilities such as wires in the housing need to be replaced or upgraded urgently, and the housing building itself needs to be maintained manually, otherwise it will not be able to meet the housing needs. Farmers will be willing to transfer the homestead if the head of the household is unable or unwilling to bear the cost of its renovation. Therefore, the homestead with long housing age have a far strengthening effect on the transfer will.

\section{Policy Implications}

Through the analysis of the logistic regression model, it can be concluded that the key influencing factors of farmers' willingness to transfer homestead in Nanhai District are the occupation type of farmers themselves, as well as the number, coverage, distance from the central areas, utilization status, and housing age. To this end, the following policy recommendations are made.

\subsection{Establish a Reasonable and Perfect Income Distribution Mechanism}

This study shows that the farmers' education level has a positive effect on the transfer intention. On the one hand, farmers with a high degree of education tend to be more inclined to develop their career in the city. On the other hand, a high degree of education means that they can understand more clearly the policy of homestead transfer, and can better protect their rights and interests with legal weapons in the transfer process. They bear relatively small circulation risks, so their willingness to transfer will be relatively high. However, in the transfer of homestead, farmers are always in a weak position. Lack of information and corresponding knowledge, it is very difficult for farmers to fully protect their legitimate rights and interests in the context of the game between multiple stakeholders. If the interests that farmer should have gained can not be guaranteed, it is difficult to expand the transfer area of homestead [7]. Therefore, in order to encourage farmers to transfer homestead, farmers main role must be played in the process of transfer, and their legitimate interests must be protected. The government should set a platform for farmers to express their request of interests, entrust a special organization to negotiate with the inflow party on behalf of farmers, implement dynamic supervision on the transfer process, formulate a reasonable incentive mechanism for the transfer of homestead, and ensure the efficient, orderly and fair operation of homestead transfer [8].

\subsection{Strengthen the Training of Farmers' Professional Skills, Improve the Quality of Farmers' Vocational Skills, and Increase Non-agricultural Employment Options}

According to the study, the number of migrant workers(out), the main source of family economy and the type of occupation in the peasant family indicate that the less the proportion of the family living in rural areas, the larger the proportion of Non-agricultural income, the more stable the life in cities and towns, the stronger the awareness of pursuing superior environment, and the higher the willingness to transfer homestead. It is suggested that the government can guide all kinds of technical schools and social schools to set special employment courses combined with market demand for farmers, recruit farmers on a large scale, create multi-form, multi-channel, multi-choice training mechanism, encourage farmers to actively participate in training, improve their own vocational ability; and through the establishment of joint training mechanism with local employers and labor export channels, farmers can achieve order-type training, so that the government can improve farmers' employment rate from various angles, so as to reduce farmers' dependence on agriculture, fundamentally solve farmers' worries about the future, and enhance farmers' willingness to transfer homestead. 


\subsection{Loosen up the Restrictions on the Subject of Homestead Transfer and Encourage Multi- purpose Development}

This study shows that the number, coverage and utilization status of homestead and housing age play a positive role in the transfer intention. However, in reality, few farmers are willing to transfer their homestead. In addition to the risk of transfer, the imperfect transfer mechanism should also be to blame. According to the current survey results, the rural homestead in Nanhai District of Foshan City is mainly transferred through leasing, but the rental market alone cannot fully accommodate all the local idle homestead. In order to make the homestead more active and bring more economic benefits, the local market demand should be satisfied, which means that the use of homestead should not be limited in self-living [9]. The government can moderately relax the restrictions on the use of homestead, meet the local rural land demand, allow village collectives or enterprises to use this land for the development of new rural industries and formats such as science and education, catering, residential accommodation, etc., which can improve the development potential of residential land and attract market participants to invest [10].

\subsection{Strengthen the Construction of Rural Social Security System}

This study demonstrates that long distance between homestead and government weakens the transfer intention. For these farmers who live far away from the city, their living conditions may be relatively poor, and homestead entails a strong security function for them. Compared with rural areas, if the family lives in the city, the level of living and consumption will increase sharply, which may make it impossible to guarantee its daily life, and at the same time, the problems of the support of the elderly and the education of the children can not be solved. [11]. If there is a lack of necessary compensation mechanism in the process of transfer, it will lead to the living difficulties of the farmers who lost land and a turbulent society may also emerge. Therefore, the government should strengthen the reform of urban and rural social security system, establish and improve public service facilities such as old-age insurance, social security and children's schooling. Also, government should provide corresponding institutional security for the farmers who transfer their homestead, so as to make up for the missing social security function. With these measures, farmers' worries about the system can be responded and consequently the transfer of homestead will be promoted.

\section{References}

[1] Wu, Y. Z., Mo, Z. B., Peng Y., Martin S., Market-driven land nationalization in China: A new system for the capitalization of rural homesteads. Land Use Policy, 2018, 70(1): 559-569.

[2] Qing, J., The Reform of Homestead System and the Increase of Farmers' Property Income [J], Rural Economy and Science-Technology, 2019, 30(19):13-15.

[3] Daniel, C., Morrison, T.H., Phinn, S., The governance of private residential land in cities and spatial effects on tree cover [J]. Environmental Science \& Policy, 2016(62)79-89.

[4] Wu, M., Yan, J., Chen, H., Study on Risk Management of Rural Homestead Transfer based on Supply and Demand Theory [J], Modern Management Science, 2017(05):30-32.

[5] Wu L., Li, H., Wen, F., et al. Study on the Governance of Rural Idle Homestead [J], Rural Economy and Science-Technology, 2019(03):44-45.

[6] Zhou, J., Explore and Deepen the Reform of "Three Rights Division" in Rural Homestead[J]. Modern Economic Research, 2019(11):117-125.

[7] Huy, H.T., Lyne, M., Ratna, N., et al. Drivers of transaction costs affecting participation in the rental market for cropland in Vietnam[J]. Australian Journal of Agricultural and Resource Economics, 2016, 60 (3): 476-492.

[8] Zhao, B., Zhang, H., A Brief Discussion on the Ways to Withdraw from Rural Homestead with Compensation [J]. Agricultural Economy. 2019(10):96-98. 
[9] Ghosh S., Chifos, C., The 1985 siting of a Toyota manufacturing plant in rural Kentucky, USA: The ensuing land use change and implications for planning[J]. Landscape and Urban Planning, 2017(167): 288-301.

[10] Bai, W., On the Reform of Rural Homestead System in the New Era[J], Western Resources, 2019 (04): $171-172$.

[11] Liu, L., Research on the Willingness of Farmers to participate in the Transfer of Gomestead Use Right -- Based on the Survey of Farmers in Dingzhou City [J]. Social Scientists, 2019(07):63-69.

[12] Sorensen. Land expropriation without compensation in South Africa. International Journal of Environmental Studies, 2019, 76(01): 5-6.

[13] Nie, J., Zhong, Z., [J], Substitution Degree of Farmland Security Function and Reaction of Farmers on the Farmland Transfer [J], China Polulation.Resources and Environment, 2015, 25(01):103-111. 